\begin{tabular}{|c|l|}
\hline Title & Two-directional N2 desorption in thermal dissociation of N2O on Rh(110), Ir(110), and Pd(110) at low temperatures \\
\hline Author(s) & Horino, H.; Rzez'nicka, I.; Kokalj, A.; Kobal, I.; Ohno, Y.; Hiratsuka, A .; Matsushima, T. \\
\hline Citation & $\begin{array}{l}\text { Journal of V acuum Science \& Technology A: V acuum, Surfaces, and Films, 20(5), 1592-1596 } \\
\text { https://doi.org/10.1116/1.1495507 }\end{array}$ \\
\hline Issue Date & 2002-09 \\
\hline Doc URL & http://hdl.handle.net/2115/5733 \\
\hline Type & article \\
\hline File Information & JVS\&TA-V SF2O(5).pdf \\
\hline
\end{tabular}

Instructions for use 


\title{
Two-directional $\mathrm{N}_{2}$ desorption in thermal dissociation of $\mathrm{N}_{2} \mathrm{O}$ on $\mathrm{Rh}(110), \operatorname{Ir}(110)$, and $\mathrm{Pd}(110)$ at low temperatures
}

\author{
H. Horino and I. Rzeźnicka \\ Department of Materials Science, Graduate School of Environmental Earth Science, Hokkaido University, \\ Sapporo 060-0810, Japan \\ A. Kokalj and I. Kobal \\ J. Stefan Institute, 1000 Ljubljana, Slovenia \\ Y. Ohno, A. Hiratsuka, and T. Matsushima ${ }^{\text {a) }}$ \\ Surface Reaction Dynamics Laboratory, Catalysis Research Center, Hokkaido University, \\ Sapporo 060-0811, Japan
}

(Received 29 October 2001; accepted 27 May 2002)

\begin{abstract}
Two-directional $\mathrm{N}_{2}$ desorption was found in $\mathrm{N}_{2} \mathrm{O}$ dissociation on $\operatorname{Rh}(110), \operatorname{Ir}(110)$, and $\operatorname{Pd}(110)$ below $160 \mathrm{~K}$ by angle-resolved thermal desorption. $\mathrm{N}_{2} \mathrm{O}(a)$ is mostly dissociated during heating procedures, emitting $\mathrm{N}_{2}(g)$ and leaving $\mathrm{O}(a)$. $\mathrm{N}_{2}$ showed four desorption peaks in the temperature range of 110-200 K. One of them commonly showed a cosine distribution, whereas the others sharply collimated off the surface normal in the plane along the [001] direction. The collimation angle was about $70^{\circ}$ on $\operatorname{Rh}(110), 65^{\circ}$ on $\operatorname{Ir}(110)$, and $43^{\circ}-50^{\circ}$ on $\operatorname{Pd}(110)$. A high-energy-atom assisted desorption model was proposed for $\mathrm{N}_{2}$ inclined emission. (C) 2002 American Vacuum Society. [DOI: 10.1116/1.1495507]
\end{abstract}

\section{INTRODUCTION}

$\mathrm{N}_{2} \mathrm{O}$ decomposition on noble metals has attracted much attention in the catalytic removal of nitrogen oxides in exhaust gases because these metals are good catalysts and $\mathrm{N}_{2} \mathrm{O}$ is the main by-product in this process. ${ }^{1}$ Furthermore, $\mathrm{N}_{2} \mathrm{O}$ itself is harmful and yields a remarkable greenhouse effect. However, its decomposition and formation mechanism on these metals is not clear. Peculiar $\mathrm{N}_{2}$ desorption observed on $\operatorname{Pd}(110)$ is expected to provide more insight into product emission dynamics. ${ }^{2-6}$ This paper is the first to report the angular distributions of desorbing $\mathrm{N}_{2}$ in the thermal dissociation of $\mathrm{N}_{2} \mathrm{O}(a)$ on $\operatorname{Rh}(110)$ and $\operatorname{Ir}(110)$ as well as $\operatorname{Pd}(110)$. Part of the desorbing $\mathrm{N}_{2}$ commonly collimated far from the surface normal in the plane along the [001] direction. The collimation angle changed significantly according to the metal that was used.

We recently found a close similarity in the angular and velocity distributions of desorbing $\mathrm{N}_{2}$ in both $\mathrm{NO}$ and $\mathrm{N}_{2} \mathrm{O}$ decompositions over Pd(110) (Refs. 2-6) and concluded that a substantial contribution to $\mathrm{N}_{2}$ emission originated from the $\mathrm{N}_{2} \mathrm{O}(a)$ intermediate in a steady-state $\mathrm{NO}+\mathrm{CO}$ reaction. Desorbing $\mathrm{N}_{2}$ with a hyperthermal energy was highly concentrated in the plane along the [001] direction and collimated at $41^{\circ}-43^{\circ}$ off the surface-normal. The inclined emission was explained to be due to decomposition of $\mathrm{N}_{2} \mathrm{O}(a)$ molecules oriented along the [001] direction, in which a nascent oxygen atom could provide a surface parallel momentum to desorbing $\mathrm{N}_{2} \cdot{ }^{2,3}$ Such oriented $\mathrm{N}_{2} \mathrm{O}$ has recently been confirmed to be stable by a density functional theory (DFT) study. ${ }^{7}$ This high-energy-atom assisted desorption model predicts larger collimation angles and higher kinetic energy on

\footnotetext{
a) Author to whom correspondence should be addressed; electronic mail: tatmatsu@cat.hokudai.ac.jp
}

rhodium and iridium than on palladium because larger amounts of energy are released in the metal-O bond formation. ${ }^{8}$

\section{EXPERIMENTS}

An UHV system with three chambers was used. ${ }^{9}$ The reaction chamber was equipped with LEED-AES, an $\mathrm{Ar}^{+}$gun, and a mass spectrometer for angle-integrated (AI) desorption analysis. The collimator house had a slit on each end and the analyzer had another mass spectrometer for angle-resolved (AR)-TDS measurements. A sample crystal was set on the top of a rotatable manipulator to change the desorption angle $(\theta$; polar angle). This angle was scanned in the normally directed plane along the [001] direction because the inclined desorption was found in this plane. ${ }^{5}$

The sample crystal was cleaned by repeated $\mathrm{Ar}^{+}$bombardments and heating in oxygen. After being flashed to high temperatures, the surface was exposed to ${ }^{15} \mathrm{~N}_{2} \mathrm{O}$ through a gas doser when the surface temperature $\left(T_{S}\right)$ was down to around $95 \mathrm{~K}$. The flashing temperature was $1200 \mathrm{~K}$ on $\mathrm{Rh}(110)$ and $1000 \mathrm{~K}$ on $\mathrm{Pd}(110)$. After this flashing, the surface showed a sharp $(1 \times 1)$ LEED pattern without higherorder spots. No reactive oxygen remained, as judged from the absence of $\mathrm{CO}_{2}$ formation in the post-TDS after $\mathrm{CO}$ exposure. The LEED pattern still showed $(1 \times 1)$ on $\mathrm{Rh}(110)$ after TDS work of $\mathrm{N}_{2} \mathrm{O}$ below about $200 \mathrm{~K}$. On the other hand, an $\operatorname{Ir}(110)$ surface was first heated in $3 \times 10^{-8}$ Torr $\mathrm{O}_{2}$ for $900 \mathrm{~s}$ at $T_{S}=870 \mathrm{~K}$ and then in $3 \times 10^{-8}$ Torr $\mathrm{H}_{2}$ for $600 \mathrm{~s}$ at $T_{S}=500 \mathrm{~K}$. It was finally heated to $1100 \mathrm{~K}$ in vacuum. The resultant surface was partially reconstructed into a missing-row structure. ${ }^{10}$ It was exposed to $\mathrm{H}_{2}$ at $0.3 \mathrm{~L}$ (Langmuir) and flashed to $1100 \mathrm{~K}$ before each experiment.

The fragmentation of ${ }^{15} \mathrm{~N}_{2} \mathrm{O}$ was separately examined in 
each mass spectrometer under a constant flow of this gas. The correction based on this fragmentation became significant only at high exposures. Hereafter, the isotope ${ }^{15} \mathrm{~N}$ is simply designated as $\mathrm{N}$.

\section{RESULTS}

After $\mathrm{N}_{2} \mathrm{O}$ exposures at $95 \mathrm{~K}$ or below it, $\mathrm{N}_{2} \mathrm{O}(a)$ mostly dissociated in the subsequent heating procedures common to the three surfaces, emitting $\mathrm{N}_{2}(g)$ and leaving $\mathrm{O}(a) . \mathrm{N}_{2}$ showed four desorption peaks in the temperature range of 110-200 K. On the other hand, $\mathrm{N}_{2} \mathrm{O}$ desorption was noticed only above exposures yielding near saturation of $\mathrm{N}_{2}$ desorption on $\mathrm{Rh}(110)$ and $\mathrm{Pd}(110)$. On $\mathrm{Rh}(110), \mathrm{N}_{2} \mathrm{O}$ desorption peaked at around $115 \mathrm{~K}$ and was completed at around $130 \mathrm{~K}$. Its peak area in the AI-form was always below $10 \%$ of that of $\mathrm{N}_{2}$. On $\operatorname{Pd}(110)$, the peak area was $<1 \%$ of that of $\mathrm{N}_{2}$ and its desorption was completed at around $150 \mathrm{~K}$. On the other hand, on $\operatorname{Ir}(110), \mathrm{N}_{2} \mathrm{O}$ desorption was noticed above one third of saturation of $\mathrm{N}_{2}$ and its peak area reached about $30 \%$ of that of $\mathrm{N}_{2}$. Thus, the $\mathrm{N}_{2} \mathrm{O}$ coverage, $\Theta_{\mathrm{N}_{2} \mathrm{O}}$, was defined as the AI-TDS peak area of $\mathrm{N}_{2}$ relative to the maximum, commonly on the three surfaces.

\section{A. $\operatorname{Rh}(110)$}

$\mathrm{N}_{2}$ desorption started at around $95 \mathrm{~K}$ and two peaks first appeared at $110 \mathrm{~K}\left(\beta_{4}-\mathrm{N}_{2}\right)$ and $167 \mathrm{~K}\left(\beta_{1}-\mathrm{N}_{2}\right)$ when the clean surface was exposed to $\mathrm{N}_{2} \mathrm{O}$ at $95 \mathrm{~K}$. Significant signals were observed between the above two peaks, suggesting the presence of additional peaks [Fig. 1(a)]. The $\beta_{4}-\mathrm{N}_{2}$ signal was enhanced in the AR form around $\theta=70^{\circ}$ as compared with that in the AI form. For the angular distribution analysis, the peak temperature and peak height of each $\mathrm{N}_{2}$ desorption were determined by curve fitting, in which a Gaussian form with fixed values for its peak position and half-width was assumed for each peak (Fig. 1). The remaining signal, after subtraction of $\beta_{1}-\mathrm{N}_{2}$ and $\beta_{4}-\mathrm{N}_{2}$, seemed to involve two peaks at around $130 \mathrm{~K}$ and $145 \mathrm{~K}$, and the signal is called $\left(\beta_{2}-\mathrm{N}_{2}+\beta_{3}-\mathrm{N}_{2}\right)$. This component was highly enhanced at high exposures and overlapped with the others. The formation of $\beta_{1}-\mathrm{N}_{2}$ at around $167 \mathrm{~K}$ was major from low exposures and showed a simple cosine distribution [Fig. 2(a)]. The signal of $\beta_{4}-\mathrm{N}_{2}$ was maximized at $\pm 70^{\circ}$ and approximated as $\cos ^{15}(\theta+70)+\cos ^{15}(\theta-70)$ [Fig. 2(b)]. The $\left(\beta_{2}-\mathrm{N}_{2}+\beta_{3}-\mathrm{N}_{2}\right)$ signal followed a similar angle dependence to $\beta_{4}-\mathrm{N}_{2}$.

We also examined the angular distribution of desorbing $\mathrm{N}_{2}$ from the clean surface exposed to $\mathrm{N}_{2}$ at $95 \mathrm{~K} . \mathrm{N}_{2}$ desorption in the subsequent heating peaked at $165 \mathrm{~K}$ below two thirds of saturation. This desorption showed a simple cosine distribution. Hence, a $\beta_{1}-\mathrm{N}_{2}$ peak was assigned to the desorption from an adsorption state as $\mathrm{N}_{2}(a)$.

\section{B. $\operatorname{Ir}(110)$}

After $\mathrm{N}_{2} \mathrm{O}$ exposure, $\mathrm{N}_{2}$ desorbed in the temperature range from $100 \mathrm{~K}$ to $210 \mathrm{~K}$ (Fig. 3). The main peaks were found at $120 \mathrm{~K}\left(\beta_{4}-\mathrm{N}_{2}\right)$ and $190 \mathrm{~K}\left(\beta_{1}-\mathrm{N}_{2}\right)$. The signal between them was still significant and involved $\left(\beta_{2}-\mathrm{N}_{2}\right.$
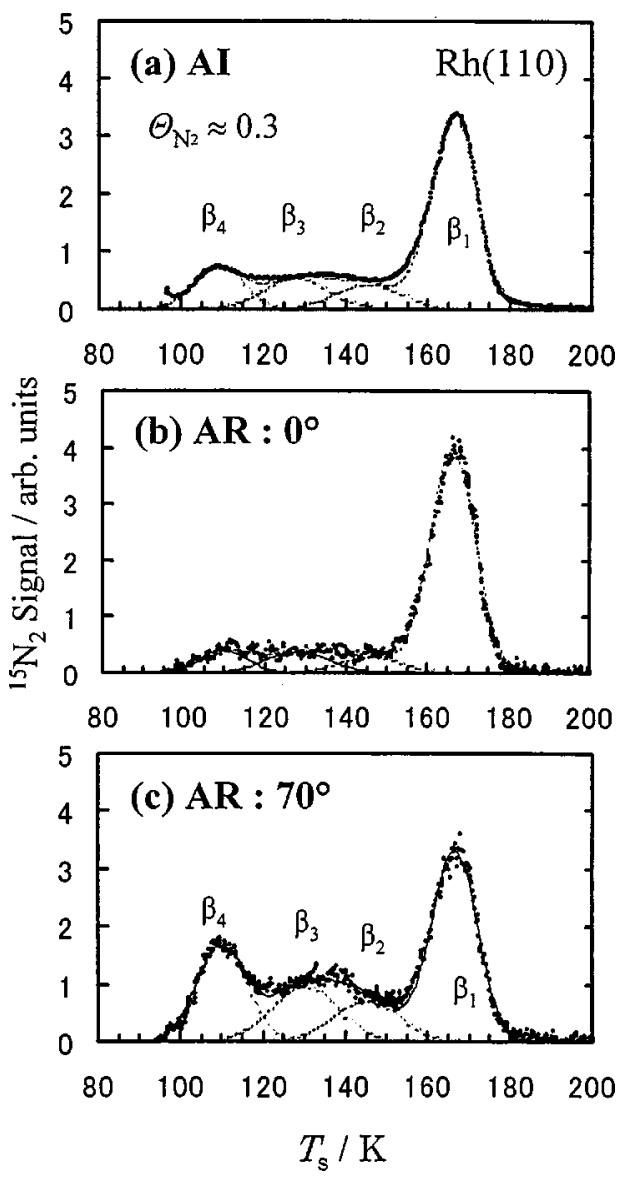

FIG. 1. TDS spectra of $\mathrm{N}_{2}$ from $\mathrm{N}_{2} \mathrm{O}$-covered $\mathrm{Rh}(110)$ at $\Theta_{\mathrm{N}_{2} \mathrm{O}}=0.3$. (a) AI-form, (b and c) AR-form at $\theta=0^{\circ}$ and $70^{\circ}$. The heating rate was 0.6 $\mathrm{K} \mathrm{s}^{-1}$. Deconvolutions shown by dotted curves are based on a Gaussian form for each peak. The solid line indicates the sum of all the components.

$\left.+\beta_{3}-\mathrm{N}_{2}\right)$ at around $145 \mathrm{~K}$ and $168 \mathrm{~K}$. It was insensitive to the desorption angle. $\beta_{1}-\mathrm{N}_{2}$ showed a simple cosine distribution and the peak temperature was very close to the $\mathrm{N}_{2}$ desorption peak position on clean $\operatorname{Ir}(110)$. This is due to desorption from a molecularly adsorbed state of $\mathrm{N}_{2} \cdot \beta_{4}-\mathrm{N}_{2}$ showed inclined desorption that collimated at $65 \pm 5^{\circ}$ and was accompanied with a cosine distribution component (Fig. 4). The signal was approximated as $\cos ^{15}(\theta+65)$ $+\cos ^{15}(\theta-65)+0.6 \cos \theta$.

\section{C. $\operatorname{Pd}(110)$}

$\mathrm{N}_{2}$ desorption showed four peaks in a temperature range of $100-160 \mathrm{~K}$. The AR-TDS spectra were sensitive to the desorption angle, as shown in Fig. 5. $\beta_{4}-\mathrm{N}_{2}$ was clearly seen only at $\Theta_{\mathrm{N}_{2} \mathrm{O}}<0.10$ in the AR form at around $\theta=35^{\circ}-65^{\circ}$ and peaked at $110 \mathrm{~K} .{ }^{11}$ The $\beta_{3}-\mathrm{N}_{2}$ peak was sharply enhanced above $\Theta_{\mathrm{N}_{2} \mathrm{O}}=0.05$ at $123 \mathrm{~K} . \beta_{1}-\mathrm{N}_{2}$ appeared at around $150 \mathrm{~K}$ as a shoulder of intense $\beta_{2}-\mathrm{N}_{2}$, becoming evident at high $\mathrm{N}_{2} \mathrm{O}$ exposures. With increasing $\Theta_{\mathrm{N}_{2} \mathrm{O}}$, $\beta_{2}-N_{2}$ increased linearly. Its formation peaked at around 134 $\mathrm{K}$ and was always major. This component was insensitive to $\theta$, showing a cosine distribution, and its peak temperature 


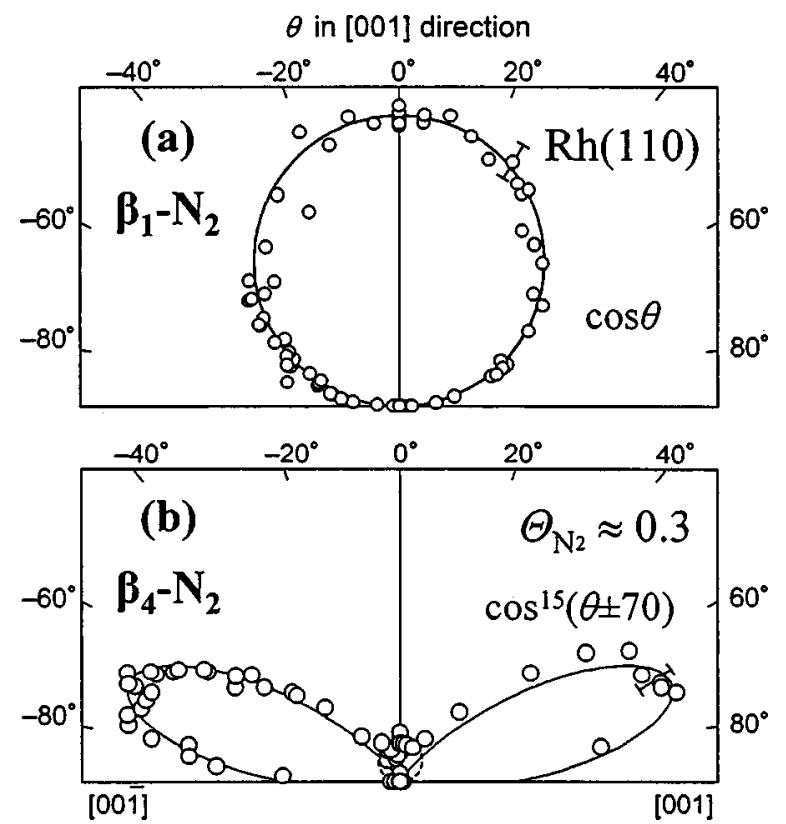

FIG. 2. Angular distributions of desorbing $\mathrm{N}_{2}$ in the plane along the [001] direction on $\mathrm{Rh}(110)$. (a) $\beta_{1}-\mathrm{N}_{2}$ at $T_{S}=167 \mathrm{~K}$ and $\Theta_{\mathrm{N}_{2} \mathrm{O}}=0.3$. (b) $\beta_{4}-\mathrm{N}_{2}$ at $T_{S}=110 \mathrm{~K}$ and $\Theta_{\mathrm{N}_{2} \mathrm{O}}=0.3$. Error bars are also shown.
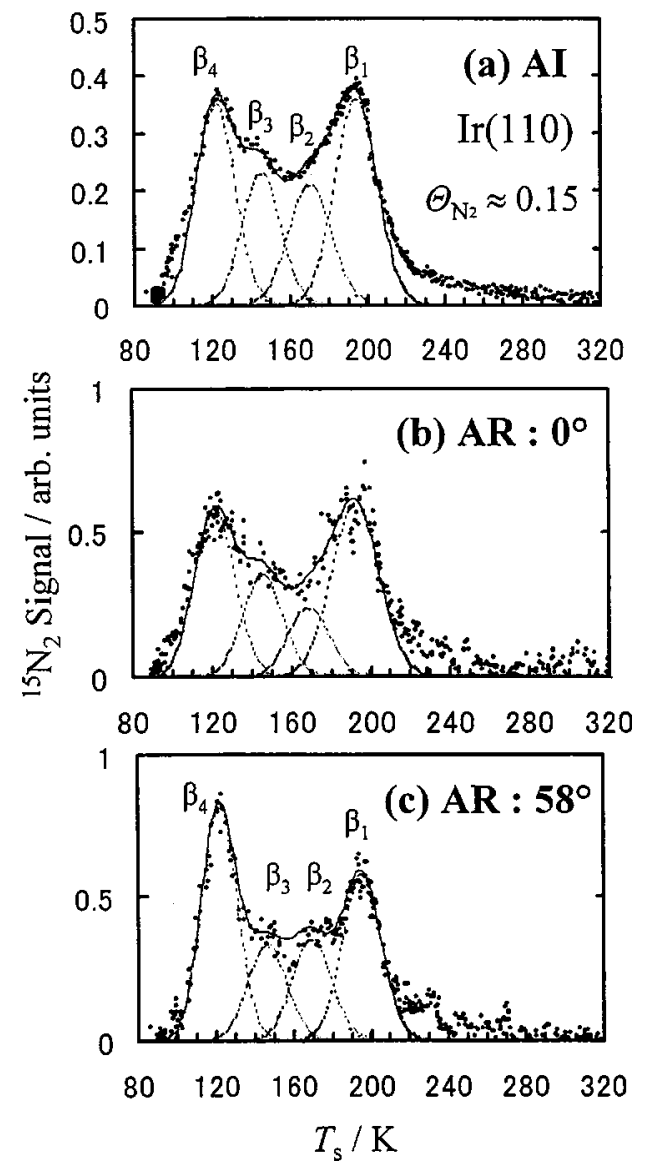

FIG. 3. TDS spectra of $\mathrm{N}_{2}$ from $\mathrm{N}_{2} \mathrm{O}$-covered $\operatorname{Ir}(110)$ at $\Theta_{\mathrm{N}_{2} \mathrm{O}}=0.15$. (a) AI-form, and (b and c) AR-form at $\theta=0^{\circ}$ and $\theta=58^{\circ}$. The heating rate was $3 \mathrm{~K} \mathrm{~s}^{-1}$. Deconvolutions shown by dotted curves are based on a Gaussian form for each peak. The solid line indicates the sum of all the components.

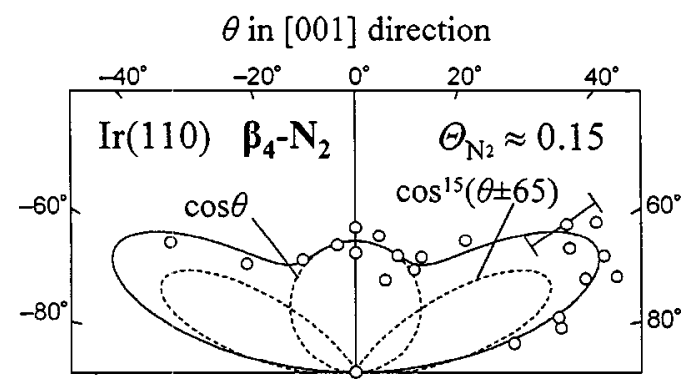

FIG. 4. Angular distribution of $\beta_{4}-\mathrm{N}_{2}$ in the plane along the [001] direction on $\operatorname{Ir}(110)$ at $T_{S}=120 \mathrm{~K}$ and $\Theta_{\mathrm{N}_{2} \mathrm{O}}=0.15$. A typical error level is shown by the inclined bar.

agreed with the desorption of $\mathrm{N}_{2}(a)$ on clean $\operatorname{Pd}(110)$. This is again due to the desorption from a molecular $\mathrm{N}_{2}$ adsorption state.

The angular distributions of the other three components are summarized in Fig. 5(c). $\beta_{4}-\mathrm{N}_{2}$ obeyed a $\cos ^{28}(\theta+50)$ $+\cos ^{28}(\theta-50)$ form at $\Theta_{\mathrm{N}_{2} \mathrm{O}}<0.10$. The collimation angle shifted from $50^{\circ}$ to $44^{\circ}$ above $\Theta_{\mathrm{N}_{2} \mathrm{O}}=0.20$ and showed a $\cos ^{50}(\theta+44)+\cos ^{50}(\theta-44)$ form. $\beta_{3}-\mathrm{N}_{2}$ collimated at $\pm 43^{\circ}$. Its signal was approximated as $\cos ^{50}(\theta+43)$ $+\cos ^{50}(\theta-43) . \quad \beta_{1}-\mathrm{N}_{2}$ obeyed a $\cos ^{50}(\theta+43)+\cos ^{50}(\theta$ -43 ) form. These powers have experimental uncertainty as $50 \pm 10$.

The $\mathrm{N}_{2}$ TDS shape changed depending on the precoverage of oxygen. No $\mathrm{N}_{2}$ was desorbed when the surface was covered in advance with oxygen to more than one-third of saturation. With increasing the preadsorbed oxygen, $\beta_{4}-\mathrm{N}_{2}$ and $\beta_{3}-\mathrm{N}_{2}$ were suppressed quickly, whereas $\beta_{2}-\mathrm{N}_{2}$ was once maximized at around $10 \%$ of saturation of oxygen and then decreased.

\section{DISCUSSION}

\section{A. Diffuse distribution}

$\mathrm{N}_{2} \mathrm{O}$ decomposition yielded four $\mathrm{N}_{2}$ desorption peaks in the range of 110-200 K. One of them commonly showed a cosine distribution. On $\mathrm{Pd}(110)$, the velocity of $\mathrm{N}_{2}$ in this peak was already analyzed to show a Maxwellian distribution at the surface temperature. ${ }^{6}$ This is consistent with desorption from the adsorption state of $\mathrm{N}_{2}$. Such $\mathrm{N}_{2}(a)$ formation may proceed below their peak temperatures as $\mathrm{N}_{2} \mathrm{O}(a)$ $\rightarrow \mathrm{N}_{2}(a)+\mathrm{O}(a)$. The peak temperature is simply determined by the heat of $\mathrm{N}_{2}$ adsorption.

This cosine component contributed about $50 \%$ of the total amount of desorbing $\mathrm{N}_{2}$ on $\mathrm{Pd}(110)$ at low $\mathrm{N}_{2} \mathrm{O}$ exposures, whereas on $\operatorname{Rh}(110)$, it was about $70 \%$. On $\operatorname{Ir}(110)$, it was roughly $80 \%$ when considering that $\beta_{4}-\mathrm{N}_{2}$ involved a cosine component to about $30 \%$ and the others were in a cosine distribution. From the desorption peak temperature, the heat of adsorption of $\mathrm{N}_{2}$ was estimated to be about $34 \mathrm{~kJ} \mathrm{~mol}^{-1}$ on $\mathrm{Pd}(110), 42 \mathrm{~kJ} \mathrm{~mol}^{-1}$ on $\mathrm{Rh}(110)$, and $38-48 \mathrm{~kJ} \mathrm{~mol}^{-1}$ on $\operatorname{Ir}(110) .{ }^{12}$ This order is fairly consistent with the fraction se- 

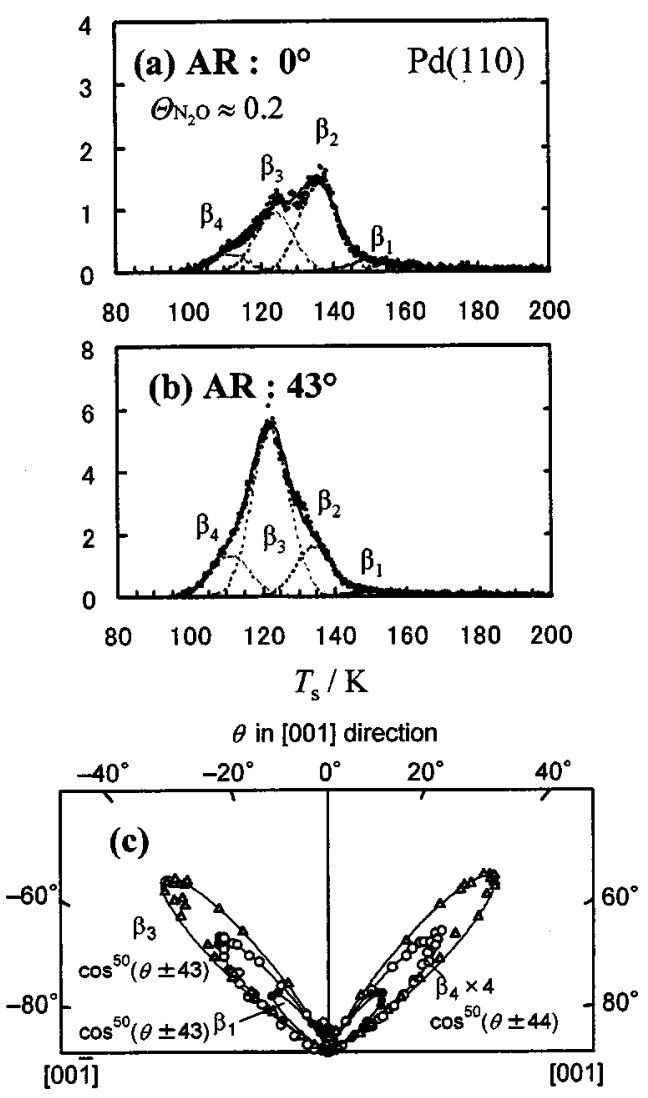

FIG. 5. AR-TDS spectra of $\mathrm{N}_{2}$ at different desorption angles from $\mathrm{N}_{2} \mathrm{O}$-covered $\mathrm{Pd}(110)$ at $\Theta_{\mathrm{N}_{2} \mathrm{O}}=0.20$. (a) $\theta=0^{\circ}$ and (b) $\theta=43^{\circ}$. The heating rate was $0.6 \mathrm{~K} \mathrm{~s}^{-1}$. Deconvolutions shown by dotted curves are based on a Gaussian form for each peak. The solid line indicates the sum of all the components. (c) Angular distribution of each $\mathrm{N}_{2}$ peak in the plane along the [001] direction. $-\beta_{1}-\mathrm{N}_{2}$ at $T_{S}=150 \mathrm{~K}$ and $\Theta_{\mathrm{N}_{2} \mathrm{O}}=1.0$, and at $\Theta_{\mathrm{N}_{2} \mathrm{O}}$ $=0.20 ; \triangle, \beta_{3}-\mathrm{N}_{2}$ at $T_{S}=123 \mathrm{~K}$ and $\bigcirc, \beta_{4}-\mathrm{N}_{2}$ at $T_{S}=110 \mathrm{~K}$.

quence of the cosine component, suggesting that a principal factor to control the trapping is the depth of the $\mathrm{N}_{2}$ adsorption potential well.

The other $\mathrm{N}_{2}$ peaks are due to direct desorption from the $\mathrm{N}_{2} \mathrm{O}(a)$ decomposition events because of their sharp angular distributions. The differences in the peak temperature are due to the different activation energies of $\mathrm{N}_{2} \mathrm{O}(a)$ decomposition. This energy may increase with increasing the amount of $\mathrm{O}(a)$ because of the decreasing vacant sites and the stabilizing effect toward the $\mathrm{N}_{2} \mathrm{O}(a) .^{13}$

\section{B. Inclined desorption}

$\beta_{1}-\mathrm{N}_{2}$ on $\mathrm{Pd}(110)$ carries a hyperthermal energy (about $\left.46 \mathrm{~kJ} \mathrm{~mol}^{-1}\right){ }^{2-5} \mathrm{~N}_{2}$ in the other inclined desorption is also expected to show high translational energy because of its sharp angular distributions. ${ }^{14}$ The collimation angle depends on the kind of metal, i.e., $70^{\circ} \pm 5^{\circ}$ on $\mathrm{Rh}(110), 65^{\circ} \pm 5^{\circ}$ on $\operatorname{Ir}(110)$, and $43^{\circ}-50^{\circ}$ on $\operatorname{Pd}(110)$. This sequence is consistent with our prediction described in the introduction.

The bent $\mathrm{N}_{2} \mathrm{O}$ molecule oriented into the [001] direction is suitable for the precursor of dissociation because it intereacts with metal also through its terminal oxygen atom which must be removed by the surface. ${ }^{7}$ After the $\mathrm{N}-\mathrm{O}$ bond is broken, the nascent $\mathrm{O}(a)$ is stabilized onto the nearest adsorption site. During this process, a large amount of energy is dissipated on account of the energy of the metal-O bond formation. The released energy on $\operatorname{Pd}(110)$ is $\approx 200 \mathrm{~kJ} \mathrm{~mol}^{-1}$ since the heat of $\mathrm{N}_{2} \mathrm{O}$ adsorption is only $25-35 \mathrm{~kJ} \mathrm{~mol}^{-1}$ and the heat of the $\mathrm{Pd}-\mathrm{O}$ formation is about $235 \mathrm{~kJ} \mathrm{~mol}^{-1}$.,11 Therefore, the fragment $\mathrm{N}_{2}$ is able to receive energy from the nascent $\mathrm{O}$ atom.

The released energy is much higher on $\mathrm{Rh}$ and Ir. It was estimated to be $\approx 350 \mathrm{~kJ} \mathrm{~mol}^{-1}$ because the heat of the metal-O bond formation is around $374 \mathrm{~kJ} \mathrm{~mol}^{-1}$ for $\mathrm{Rh}$ and $378 \mathrm{~kJ} \mathrm{~mol}^{-1}$ for $\mathrm{Ir}^{8}$ Hence, the experimentally observed trend in the collimation angle can be explained because it is reasonable to assume that the larger the dissipated energy release from the metal-O bond formation and the associated force is presumably acting along the [001] direction on the remaining $\mathrm{N}_{2}$ fragment, the more the collimation angle will shift from the [110] surface normal direction.

The energy transfer mechanism is not clear at present. The nascent $\mathrm{N}_{2}$ may be repelled by the surface along the surface normal due to Pauli repulsion because the bulky $\mathrm{N}_{2}$ molecule is formed in a close proximity to the surface. Such repulsion was reported in the combinative desorption as $2 \mathrm{~N}(a)$ $\rightarrow \mathrm{N}_{2}(g)$ on $\mathrm{Ru}(001)$ and $\mathrm{Cu}(111) .{ }^{15-17}$ The force is exerted to the product along the surface normal because normally directed desorption was observed. However, the normally directed force in $\mathrm{N}_{2} \mathrm{O}$ dissociation is not expected to be as large as that in the combinative desorption because the location of $\mathrm{N}$ in $\mathrm{N}_{2} \mathrm{O}(a)$ is further from the surface than that of the adsorbed nitrogen atom. For inclined desorption, additional forces must be operative towards the product $\mathrm{N}_{2}$ into the inclined way. This force is likely to come from the nascent oxygen.

A higher translational energy is generally expected for molecules with sharper angular distributions, ${ }^{18}$ although the translational energy generally depends on the surface crystal azimuth. ${ }^{14}$ The above model predicts that the translational energy on $\operatorname{Rh}(110)$ and $\operatorname{Ir}(110)$ is higher than that on $\operatorname{Pd}(110)$, i.e., the angular distribution on $\operatorname{Pd}(110)$ must be broader than that on the others. However, the sharpness of the angular distribution was observed in an opposite way. This discrepancy must be directly examined by velocity distribution measurements.

\section{SUMMARY}

The angular distribution of desorbing $\mathrm{N}_{2}$ in $\mathrm{N}_{2} \mathrm{O}$ dissociation on $\mathrm{Rh}(110), \operatorname{Ir}(110)$, and $\operatorname{Pd}(110)$ was analyzed by angle-resolved thermal desorption. The results are summarized as follows:

(1) $\mathrm{N}_{2}$ showed four desorption peaks in the range of 110$200 \mathrm{~K}$. One of the peaks commonly shows a cosine distribution due to desorption from $\mathrm{N}_{2}(a)$.

(2) $\mathrm{N}_{2}$ desorbing in the other peaks sharply collimates off the surface normal into the [001] direction. The collimation angle was about $70^{\circ}$ on $\operatorname{Rh}(110), 65^{\circ}$ on $\operatorname{Ir}(110)$, and $43^{\circ}-50^{\circ}$ on $\operatorname{Pd}(110)$. 


\section{ACKNOWLEDGMENTS}

Ivan Kobal acknowledges the support he received from the Japan Society for the Promotion of Science (JSPS) (2001). Izabela Rzeźnicka is indebted to the Ministry of Education, Science, Sports, and Culture of Japan for a scholarship (2000-2004). This work was supported in part by Grant-in-Aid No. 13640493 for General Scientific Research from JSPS.

Presented at the IUVSTA 15th International Vacuum Congress, the AVS 48th International Symposium, and the 11th International Conference on Solid Surfaces, San Francisco, CA, 28 October-2 November 2001.

${ }^{1}$ V. I. Pǎrvulescu, P. Grange, and B. Delmon, Catal. Today 46, 233 (1998). ${ }^{2}$ Y. Ohno, K. Kimura, M. Bi, and T. Matsushima, J. Chem. Phys. 110, 8221 (1999).

${ }^{3}$ I. Kobal, K. Kimura, Y. Ohno, and T. Matsushima, Surf. Sci. 445, 472 (2000).

${ }^{4}$ I. Kobal, K. Kimura, Y. Ohno, H. Horino, I. Rzeźnicka, and T. Matsushima, Stud. Surf. Sci. Catal. 130, 1337 (2000).

${ }^{5}$ I. Rzeźnicka, Y. Ohno, I. Kobal, H. Horino, K. Kimura, and T. Mat- sushima, in Heterogeneous Catalysis, in Proceedings of the 9th International Symposium, edited by L. Petrov, Ch. Bonev, and G. Kadinov, 2000, p. 97 (unpublished).

${ }^{6}$ Y. Ohno, I. Kobal, H. Horino, I. Rzeźnicka, and T. Matsushima, Appl. Surf. Sci. 169/170, 273 (2001)

${ }^{7}$ A. Kokalj, I. Kobal, H. Horino, Y. Ohno, and T. Matsushima, Surf. Sci. 506, 196 (2002).

${ }^{8}$ D. L. Hildenbrand and K. H. Lau, Chem. Phys. Lett. 319, 95 (2000).

${ }^{9}$ T. Matsushima, Surf. Sci. 127, 403 (1983).

${ }^{10}$ T. Matsushima, Y. Ohno, and K. Nagai, J. Chem. Phys. 94, 704 (1991).

${ }^{11}$ H. Horino, S. Liu, A. Hiratsuka, Y. Ohno, and T. Matsushima, Chem. Phys. Lett. 341, 419 (2001).

${ }^{12}$ D. E. Ibbotson, T. S. Wittrig, and W. H. Weinberg, Surf. Sci. 110, 313 (1981).

${ }^{13}$ H. H. Huang, C. S. Seet, Z. Zou, and G. Q. Xu, Surf. Sci. 356, 181 (1996).

${ }^{14}$ T. Matsushima, Heterog. Chem. Rev. 2, 51 (1995).

${ }^{15}$ T. Matsushima, Surf. Sci. 197, 287 (1988).

${ }^{16}$ M. J. Murphy, J. F. Skelly, and A. Hodgson, J. Chem. Phys. 109, 3619 (1998).

${ }^{17}$ M. J. Murphy, J. F. Skelly, A. Hodgson, and B. Hammer, J. Chem. Phys. 110, 6954 (1999).

${ }^{18}$ G. Comsa and R. David, Surf. Sci. Rep. 5, 145 (1985). 